\title{
Thermal properties and stability of Catalan Modernist blue and green enamels
}

\author{
Martí Beltrán ${ }^{1}$, Fiona Brock ${ }^{2}$, Trinitat Pradell ${ }^{1}$ \\ ${ }^{1}$ Physics Department and Barcelona Research Centre in Multiscale Science and Engineering, \\ Universitat Politècnica de Catalunya, Campus Diagonal Besòs, Av. Eduard Maristany, 10-14 \\ 08019 Barcelona, Spain \\ ${ }^{2}$ Cranfield Forensic Institute, Cranfield University, Defence Academy of the United Kingdom, \\ Shrivenham, SN6 8LA UK.
}

\begin{abstract}
Stained glass is a fragile component of our Cultural Heritage. In particular, the stained glass produced during the last decades of the 19th century and first decades of the 20th century is characterised by the use of a new type ready-to-use enamels. Stained glass was used for the windows of buildings, and a large part of it is exposed to weathering and consequently to deterioration. This study analyses the collection of materials used in one of the most important stained glass Modernist workshops in Barcelona. The chemical composition is determined (and pigments identified) by means of Laser Ablation Inductively-Coupled Plasma Mass Spectrometry (LA-ICP-MS) and X-Ray Diffraction (XRD) and the thermal properties of the enamels measured by Differential Scanning Calorimetry (DSC) and Hot Stage Microscopy (HSM). The enamels are made of a lead-zinc borosilicate glass characterised by its low sintering temperatures and high stability against chemical corrosion, in particular to water corrosion. However, the relatively narrow range of firing temperatures necessary for correct adherence of the enamels to the contemporary glass base may have required the addition of a high lead borosilicate flux, which would have increased the lead content of the enamel, decreasing the firing temperature but also its stability.
\end{abstract}

Keywords: lead borosilicate glass, Modernist enamels, chemical stability, softening temperature 


\section{Introduction}

Stained glass made in flat panels was used from the Middle Ages for the windows of important buildings, in particular cathedrals. The gradual abandonment of stained glass since the $16^{\text {th }}$ century by a new architecture that preferred the clarity of transparent windows resulted in some loss of the know-how and development of new techniques ${ }^{1}$. In the second half of the $15^{\text {th }}$ century and beginning of the $16^{\text {th }}$ century blown colour glass was formed by one or more thin microlayers of colour glass within transparent glass which has a remarkable artistic quality compared to the later flat homogeneous coloured glass. ${ }^{2}$ They were subsequently substituted by cold paints and enamels (that is pigments which could be fused on ceramic glazes and glass objects) from the second half $16^{\text {th }}$ century with continuity in the $17^{\text {th }}$ and $18^{\text {th }}$ centuries. The renewed interest in medieval art in the $19^{\text {th }}$ century led to the recovery and restoration of medieval stained glass windows, which together with the outburst of the decorative arts (art Nouveau) widely followed all over Europe and in America ${ }^{3}$ resulted in a renewed interest in the production of stained glass. The movement was particularly innovative in Catalonia ${ }^{4}$, Modernisme, and in particular in Barcelona in the last decades of the $19^{\text {th }}$ century until the end of the First World War. In fact, the possibility of applying the enamel with a brush over a transparent glass was really useful to obtain artistic results and the process was highly acclaimed by artists, conservators and restorers with the consequent proliferation of enamel manufacture industries.

The enamels have two different parts: the colouring part and the vitreous part. The vitreous part is a crushed glass to which transition metals (cobalt, copper, manganese, iron, etc.) and/or pigment particles, microcrystallites (tin oxide, lead antimony oxide, etc.) and nanocrystallites (cuprite, copper, silver and gold) were added to produce a wide range of transparent, translucent hues or opaque paints (grisailles with iron and manganese oxides). They were crushed and mixed with water and painted over the transparent glass, then fired to a temperature high enough to soften the enamel and fuse it into the base glass.

The stained glasses are functional window glasses and consequently have been exposed for over centuries to the inclemency of weather and solar irradiation ${ }^{5-9}$. The deterioration of blue enamels from the $16^{\text {th }}$ and $17^{\text {th }}$ centuries has been related to the chemical composition (potash rich) ${ }^{7,8}$ but also to the higher thermal expansion 
coefficients of the enamels (lead potash glass) compared to those of the base glass responsible for the formation of cracks ${ }^{5,6,8,9}$. However, the nature of the $16^{\text {th }}, 17^{\text {th }}$ and even $18^{\text {th }}$ century enamels ${ }^{10}$ is very different from those of the late $19^{\text {th }}$ century. The proliferation of enamel manufacture industries is also linked to the development of new glasses incorporating lead oxide, borax or boric acid, in many cases with important stability problems such as crizzling (lack of stabilisers) or solarisation (manganese oxidation). $^{11}$

In particular, the green and blue enamels produced between 1880 and 1920 by important workshops from Barcelona appear considerably deteriorated, Figure 1. The deterioration of blue and green enamels is not exclusive to the $19^{\text {th }}$ century Catalan workshops but has also been recorded in contemporary stained glass from England ${ }^{12}$. In fact, the deterioration of glass-paintings is already described in the late $19^{\text {th }}$ century in England ${ }^{13}$; the deterioration of the paint was associated with the use of a lead-borate obtained from a solution of borax and lead nitrate, which was added to reduce the melting temperature of the paint. Barff ${ }^{14}$ states that "the action of moisture causes the dissolution of borax" and the loss of the paint.

$<$ Figure 1 $>$

Lead oxide together with borax or boric acid were in fact added to the enamels to decrease their viscosity and reduce their softening point. They are common fluxes, which in large quantities generate glass forming structures. However, borosilicate and lead borate glasses are known to generate immiscible liquids and therefore produce heterogeneous glass ${ }^{15}$. Moreover, the presence of colourants, transition metals dissolved in the glass may also affect the stability of the enamel ${ }^{16}$.

However, the deterioration of the enamels was in many cases recorded only a few years after their production, which suggests that weathering might not be the sole cause ${ }^{12}$. In fact, one of the most important issues in the conservation of the enamels is the quality of its adherence, and this depends on the thermodynamic properties of both the substrate glass (window blown glass) and the decorative layers (enamels and grisailles) ${ }^{6,2}$. The glass transition and softening temperatures determine the range of firing temperatures necessary to obtain a correct adherence. 
Above the glass transition temperature $\left(\mathrm{T}_{\mathrm{g}}\right)$, the glass behaves as a liquid $\log (\eta(\mathrm{Pa} \cdot \mathrm{s})) \sim 12.3-{ }^{18}$. The deformation point $\left(\mathrm{T}_{\mathrm{d}}\right)$ is the temperature at which the dilatation of the glass stops in a dilatometer and corresponds to a viscosity of $\log (\eta(\mathrm{Pa} \cdot \mathrm{s}))=10.5$. This point marks the beginning of the softening range, which depends on the force applied to the glass, the highest temperature is given by the Littleton softening point $\left(\mathrm{T}_{\mathrm{s}}\right)$ defined as those for which the glasses deform under its own weight: $\log (\eta(\mathrm{Pa} \cdot \mathrm{s}))=6.6$.

The enamels should be fired at a temperature above the softening point to obtain a homogeneous glass. Moreover, the atomic diffusion coefficient of the slowest element necessary for a good inter-diffusivity of the enamels and the base glass increases dramatically at the glass transition temperature ${ }^{17}$. Therefore, the glass transition temperature of the base glass has to be reached in order to obtain a good adherence of the enamel but at the same time the softening temperature of the base glass should not be reached to avoid its damage. Consequently, the optimal firing temperature is a compromise between the base glass softening and glass transition temperatures and the enamel softening temperature. Moreover, if the viscosity of the enamels is too high during firing, large bubbles may be produced ${ }^{5,6,2}$. The large surface/volume ratio is also a handicap to the enamels' preservation. It is obvious that depending on the composition of the base glass and the enamels, this restriction may leave a very narrow temperature range.

Consequently, problems of adherence of the enamels may also be affected by the composition of the base glass. In the period between 1835 and 1930 the Leblanc process for the manufacture of sodium carbonate from common salt was introduced; previously, the soda was obtained from plant or wood ashes which contained many other elements such as $\mathrm{Al}, \mathrm{Mg}, \mathrm{Ca}$ which acted as glass stabilizers, and as a consequence the composition of the window glasses changed during this period becoming less stable ${ }^{19}$. Furthermore, the beginning of the $20^{\text {th }}$ century is characterised by the start of the production of flat glass by mechanical means that progressively substituted blown glass ${ }^{20}$, with the consequent modification of the window glass composition to one better adapted to the needs of the mechanical process. 
Finally, in order to ensure a good adherence of the enamels to the base glass, the thermal expansion coefficients of enamels and base glass should match avoiding the development of tensile stresses which lead to the formation of cracks; this has previously been noted as one of the main reasons for the flaking of $16^{\text {th }}$ and $17^{\text {th }}$ century enamels $5,6,9$.

The data presented herewith are the first obtained on thermal properties, microstructure and chemical composition of a collection of blue and green enamels used in one of the most important stained glass workshops in Barcelona during the Modernist period, Rigalt, Granell \& cia. It was founded in 1890 by Antoni Rigalt i Blanch (1850-1914) and Jeroni F. Granell i Manresa (1868-1923), later Granell \& cia (1923-1931) ${ }^{4}$. Before closing the company, the materials were acquired by J.M. Bonet Vitralls S.L., a stained glass company dedicated since 1923 to the production and restoration of stained glass. The enamels studied belong to the collection of the J.M. Bonet Vitralls S.L., which includes the documentation and materials used for the production of the stained glasses from Rigalt, Granell \& cia. The pots containing enamel powder had labels from various manufacturing companies from the period such as Wengers, Lacroix and L'Hospied, and have different composition and microstructure. Adolphe Lacroix was at the forefront of developing a new type of enamel, as described in his 1872 treatise "Des couleurs vitrifiables et de leur employ pour la peinture sur porcelain, faience, vitraux" ${ }^{21}$. Wengers is a British company established in Etruria, Stoke-on-Trent, by Albert Francis Wenger (c1840-1924). In 1874 the company advertised that they had 'crystallised boracic acid, chemically pure, for the manufacture of China, Earthenware, and Enamel Colours', and in 1914 they appear as "Manufacturers of colours and chemicals for potters, glazed brick manufacturers, glassmakers and enamellers on metal" 22. Thompson L'Hospied \& Co Ltd was founded near Stourbridge, UK, - a town known for glass production since the early 1600s - by Charles Herbert Thompson, a chemist with commercial interests in England and France. Thompson is known for the invention in 1895 , of the so called Verre sur Verre enamelled glass. ${ }^{22}$

The stability of the blue and green enamels from the workshop is investigated. The chemical composition, microstructure and thermal properties of the enamels used in the Rigalt, Granell \& cia, workshop are determined. Laser Ablation Inductively-Coupled Plasma Mass Spectrometry (LA-ICP-MS) was used to determine the chemical composition of the enamels because it is capable of the quantification of boron and also 
of minor and trace elements. The pigment particles were identified by X-ray Diffraction (XRD). Thermal properties including the glass transition for the enamels and softening temperatures for synthetic glasses obtained matching the enamels' compositions were determined by Differential Scanning Calorimetry (DSC) and Hot Stage Microscopy (HST). The range of firing temperatures and stability of the enamels on both contemporary and the modern base glasses used for restoration is determined.

\section{Materials and method}

The blue and green enamels studied belong to the collection of the J.M. Bonet Vitralls S.L., which includes the documentation and materials used for the production of the stained glasses from Rigalt, Granell \& cia. The collection of materials includes the powders used to produce four different blue enamels, three transparent ones from Wengers (E33), L'Hospied (E122) and Lacroix (E115) and one half opaque one from Lacroix (E114). Additionally, three green enamels from Lacroix, one opaque (E34) and two transparent (E89 and E121) were studied. The set also included what was labelled as fondant (flux) from Lacroix (F1) and the grisaille (G1) used by the Rigalt, Granell \& cia workshop. A glass from a window of the modernist building Casa Ametller (ca. 1900) and a modern blown glass (ca. 1950) were also analysed.

The enamel powder was mixed with water, applied over the base glass with a brush and fired. The painted glass was first heated up to $400^{\circ} \mathrm{C}$ for over two hours, kept at this temperature for 30 minutes, then heated at a constant rate of $2.5^{\circ} \mathrm{C} / \mathrm{min}$ to $590^{\circ} \mathrm{C}$, kept at this temperature for 20 minutes and, finally, left to cool naturally to room temperature ( $\sim 24$ hours). The blue and green enamels obtained are shown in Figure 2.

$<$ Figure 2 $>$

Based on the Modernist enamels analyses, a selection of synthetic glasses with the same chemical composition after subtracting the pigment particles was prepared using commercial reagents $\left(\mathrm{SiO}_{2}, \mathrm{PbO}, \mathrm{ZnO}\right.$ and $\left.\mathrm{H}_{3} \mathrm{BO}_{3}\right) .200 \mathrm{~g}$ of each mixture was melted in a platinum crucible. Raw materials were heated at a rate of $5^{\circ} \mathrm{C} / \mathrm{min}$ from room 
temperature to $850^{\circ} \mathrm{C}$ in air, and kept at this temperature for $1 \mathrm{~h}$. The glasses were then cast by pouring the liquid over a cold copper surface.

The composition of the powders and enamels prepared from them from the Rigalt, Granell \& cia workshop was determined by LA-ICP-MS using a direct solid laser ablation sampling system ${ }^{2}$ (Q switched Nd:YAG ESI $213 \mathrm{~nm}$ laser ablation system, New Wave Research) coupled to a quadrupole ICP-MS (Thermo Scientific XSERIES 2), operating in standard mode with an Xt cone). After placing the samples in the ablation chamber (flushed with $\mathrm{He}$ at a rate of $500 \mathrm{ml} \cdot \mathrm{min}^{-1}$ ), the targets were ablated with 20-50 s spot-mode analyses with a spot size of $80 \mu \mathrm{m}$ on the frontal section of the applied enamel at $10 \mathrm{~Hz}$ laser frequency, fluency of about $12 \mathrm{~J} / \mathrm{cm}^{2}, 20 \mathrm{~ms}$ dwell time per amu, 15 sweeps per replicate and 3 spot replicates per analysis. Several replicates on the dry gas were carried out in each set to establish the background prior to ablation. A preablation time of about 15-20 s was selected in order to reduce any contaminations or alterations of the outer layers. Instrumental drift was monitored throughout the analysis by measuring synthetic certified reference glasses (NIST 612 and 610) up to every 9 measurements within each run. To improve the instrument sensitivity, lower background noise, and reduce oxidised species, the ICP parameters (including RF power, ion lens voltage and sampling position within the plasma, extraction voltage, and gas flow rates) were fine-tuned at the beginning of every set of analysis by continuously ablating on a reference glass (NIST 612) using the same working conditions chosen for the analyses. The internal standard independent (ISI) method was used to calculate the elemental concentration ${ }^{23}$. Within this method the summation of the element oxides is assumed to constitute $100 \%$ of the sample. The accuracy was evaluated with respect to Corning Museum of Glass (CMG) A. The results achieved on Corning A were very similar to other runs using similar analytical equipment ${ }^{24}$.

XRD analysis of the powders and enamels prepared from them was also performed to determine the presence and nature of crystalline particles. The surface of the enamels was directly analysed using a PANalytical X'Pert PROMPD Alphal powder diffractometer with Bragg-Brentano $\theta / 2 \theta$ and $\mathrm{Cu}-\mathrm{K} \alpha$ radiation. Measuring conditions were $4^{\circ}-100^{\circ} 2 \theta$, step size of $0.017^{\circ}$ and measuring time of $150 \mathrm{~s}$. 
UV-Vis transmittance measurements were obtained from the enamels using a double beam UV-Vis spectrophotometer (Shimadzu 2700) with a spot size of $3 \mathrm{~mm} \times 1 \mathrm{~mm}$ and $1 \mathrm{~nm}$ resolution, using a D65 standard illumination source.

The glass transition temperature of the Modernist enamels and synthetic glasses was determined by Differential Scanning Calorimetry (DSC) with a Netzsch F404 Pegasus instrument. The enamel powder was transferred into an alumina pan and heated at $20^{\circ} \mathrm{C} / \mathrm{min}$ rate from room temperature to $700^{\circ} \mathrm{C}$ in air, before being cooled to $30^{\circ} \mathrm{C}$ and followed by an isotherm for $30 \mathrm{~min}$. Afterwards, the enamel was heated for a second time following the same thermal path. ${ }^{18,25,26}$

The temperatures related to fixed viscosity points in the softening range defined for Hot Stage Microscopy (HSM) according to the German rule DIN $51730{ }^{27}$ were determined for the synthetic enamels using the HSM equipment in the Department de Mineralogia, Petrologia i Geologia Aplicada of the Geology Faculty, Universitat de Barcelona ${ }^{28}$. HSM is a suitable technique to study the behaviour of glass viscosity with temperature. ${ }^{29,30}$. The synthetic glasses were ground and sieved to obtain fine $(45 \mu \mathrm{m})$ powder which was mixed with a $1 / 20$ solution of Elvacite in acetone and pressed into a cylinder ( $3 \mathrm{~mm}$ x $3 \mathrm{~mm}$ ) in a uniaxial press. The cylinders were place in a horizontal silicon carbide furnace and heated to $800^{\circ} \mathrm{C}$ with a heating rate of $7^{\circ} \mathrm{C} / \mathrm{min}$. Pictures of the cylinder were taken every 2 min during the first part of the experiment and every $3 \mathrm{~s}$ above $500^{\circ} \mathrm{C}$. The pictures were recorded with ProgRes Capture Pro software and the images were analysed using the Hot-Stage software, developed by the Departament de Llenguatges $i$ Sistemes Informàtics, Universitat Politècnica de Catalunya. The temperatures corresponding to the characteristic viscosity points (first shrinkage, maximum shrinkage, softening, ball, half ball and flow) were determined relative to the geometrical changes of the cylinder during heating ${ }^{28}$.

\section{Results and discussion}

Both the original powders from the Rigalt, Granell \& cia workshop and the enamels produced were analysed. The chemical composition of powders and enamels did not differ appreciably; consequently we can affirm that the chemical composition of the enamels does not change with firing. The chemical composition of the blue and green enamels is shown in Table I. 
$<$ Table I $>$

On the contrary, the crystalline particles related to the colourants show some differences between the original powders and enamels and also among the enamels. The main difference is the presence of some lead carbonate $\left(\mathrm{PbCO}_{3}\right)$ which is related to the weathering of the powder after 100 years, which naturally reacts and decomposes after firing. The pigment particles from the blue and green enamels are the same before and after firing but vary between the different companies (Wengers, l'Hospied and Lacroix), and are shown in Figure 3. E33 (Wengers) contains particles of cobalt aluminate $\left(\mathrm{CoAl}_{2} \mathrm{O}_{4}\right)$, a high temperature spinel structure. Cobalt is also the main colourant in the other blue enamels but appears dissolved in the enamel. However, E114 and E115 also contain small quantities of cassiterite $\left(\mathrm{SnO}_{2}\right)$; this acts as a white opacifier added to reduce the transparency of the enamels. Only one of the three green enamels (E34) contains pigment particles: Naples yellow $\left(\mathrm{Pb}_{2}(\mathrm{Sb}, \mathrm{Sn})_{2} \mathrm{O}_{7}\right)$, a yellow opacifier, and cochromite $\left(\mathrm{Co}(\mathrm{Cr}, \mathrm{Al})_{2} \mathrm{O}_{4}\right)$, a high temperature spinel containing cobalt and chromium. The other two green enamels contain $\mathrm{Cu}^{2+}$ dissolved in the glass.

Contrarily to what is found in the enamels, the pigment particles of the grisaille (G1) change after firing. Initially the grisaille powder contained hematite $\left(\mathrm{Fe}_{2} \mathrm{O}_{3}\right)$ and pyrolusite $\left(\mathrm{MnO}_{2}\right)$; after firing hematite, melanotekite $\left(\mathrm{Pb}_{2}(\mathrm{Fe}, \mathrm{Mn})_{2} \mathrm{Si}_{2} \mathrm{O}_{9}\right)$ and jacobsite, an iron-rich spinel $\left(\mathrm{Fe}_{2} \mathrm{MnO}_{4}\right)$, are found.

$<$ Figure 3 $>$

The color coordinates (Cie Lab*) of the enamels were also calculated from the transmittance UV-Vis spectra and are shown in Table II. The enamels containing pigment particles, E33, E34 and E114 and E115 show a low $L^{*}$, are more opaque, compared to those which do not contain pigment particles, E121 and E89, which are more transparent. E33 and E34 contain colour pigment particles (blue and green and yellow respectively). Consequently they have a more saturated colour compared to the 
transparent enamels and also compared to E114 and E115 which contain white particles, cassiterite, which gives opacity (high index of refraction) but no colour.

From the above data, the composition of the glassy part of the enamel is evaluated. The main components of the enamels, grisaille and flux are $\mathrm{B}_{2} \mathrm{O}_{3}, \mathrm{PbO}, \mathrm{SiO}_{2}$ and $\mathrm{ZnO}$. Small amounts of $\mathrm{Al}_{2} \mathrm{O}_{3}, \mathrm{CaO}, \mathrm{MgO}, \mathrm{K}_{2} \mathrm{O}$ (below $0.5 \%$ ) are observed, most probably associated with the impurities present in the sand used to produce the enamels. Although some of the enamels contain $\mathrm{Al}_{2} \mathrm{O}_{3}$ in higher amounts (E33 and E34), this is due to the presence of pigment particles containing aluminium $\left(\mathrm{CoAl}_{2} \mathrm{O}_{4}\right.$ and $\mathrm{Co}(\mathrm{Cr}, \mathrm{Al})_{2} \mathrm{O}_{4}$ respectively). The amount of $\mathrm{Na}_{2} \mathrm{O}$ present is also higher in some cases, but still below 2.5\%: it could be related to impurities of the sand, to the use of borax as a source of boron, or be associated with the pigment particles (it is common to add a flux to help the reaction of the raw compounds during sintering of the pigment particles). The chemical composition of the enamels after subtracting the pigment particles and colourants is in all the cases a high lead $(>50 \% \mathrm{PbO})$ with variable amounts of $\mathrm{B}_{2} \mathrm{O}_{3}$ and $\mathrm{ZnO}$.

All the green and blue enamels are lead-zinc borosilicate glasses. Borosilicate glasses were invented at the end of the $19^{\text {th }}$ century contemporarily to the invention of the enamels by Adolphe Lacroix. The addition of $\mathrm{PbO}, \mathrm{BaO}$ or $\mathrm{ZnO}$ to the borosilicate glass gives rise to low-melting glasses which may be used as solders. In borosilicate glasses lead has a dual role both as network former and network modifier. For lead borosilicate glasses, like many other borosilicate glasses, show phase separation upon cooling and opaque glasses are often obtained 15,31,32.

A peculiarity of borate containing glasses, is the fact that as modifier oxides are added to $\mathrm{B}_{2} \mathrm{O}_{3}$ (or to binary $\mathrm{B}_{2} \mathrm{O}_{3}-\mathrm{SiO}_{2}$ ), the network of trigonal $\mathrm{BO}_{3}$-units (and tetrahedral $\mathrm{SiO}_{4}$-units) is not depolymerized by the formation of non-bridging oxygen atoms. Instead, trigonal $\mathrm{BO}_{3}$ units react with the added modifier oxide and form a [BO4]tetrahedral, which negative charge is balanced by the cation of the modifier oxide. Depending on the type of modifier oxide, a maximum of $\mathrm{BO}_{4}$ units is reached at $\mathrm{MO} / \mathrm{B}_{2} \mathrm{O}_{3}=0.5\left(\mathrm{SiO}_{2} \text { can be seen as inactive solvent for low alkali additions }\right)^{33-36}$. An equilibrium exists between trigonal and tetrahedral metaborate $\left(\mathrm{BO}_{3}{ }^{-}<=>\left[\mathrm{BO}_{4}\right]^{-}\right)$. Nonbridging oxygen atoms become dominant at higher modifier oxide addition, and the known depolymerization of the glass network occurs. 
A dense transparent glass with a low softening temperature and a relative good resistance against water corrosion is obtained for compositions of $30-40 \mathrm{~mol} \% \mathrm{PbO}$ and $\mathrm{B}_{2} \mathrm{O}_{3}: \mathrm{SiO}_{2}$ ratios between $2: 1$ to $2: 3^{31}$. $\mathrm{ZnO}$ acts in a similar way to $\mathrm{PbO}$ but with a lower effect on the softening temperature and density ( $\mathrm{ZnO}$ favours the trigonal metaborate $\mathrm{BO}_{3}{ }^{-}$over the tetrahedral $\left[\mathrm{BO}_{4}\right]^{-37}$, and can instead act as glass former when incorporated as $\left[\mathrm{ZnO}_{4}\right]^{-}$. Zinc borosilicate glasses have (with $\mathrm{B}_{2} \mathrm{O}_{3}: \mathrm{SiO}_{2}: \mathrm{ZnO}=30: 20: 50$, 30:10:60 and 20:20:60) a narrower glass forming ability than lead borosilicate glasses. The progressive depolymerisation produced by the addition of lead increases the thermal expansion coefficient $\left(6-12 \cdot 10-6 \mathrm{~K}^{-1}\right)$ while the incorporation of zinc gives glasses with a lower thermal expansion coefficient $\left(4-5 \cdot 10-6 \mathrm{~K}^{-1}\right){ }^{38}$. Consequently, lead borosilicate glasses with 30 to $40 \mathrm{~mol} \% \mathrm{PbO}$ show a low softening temperature and a thermal expansion coefficient matching those of the base glass while retaining a high resistance to chemical corrosion and transparency ${ }^{31,33}$.

As well as the enamels, a grisaille (G1) and a fondant (flux, F1) from the workshop were also analysed. The flux was also determined to be a lead borosilicate glass but containing a lower boron and significant higher lead content $\left(\mathrm{B}_{2} \mathrm{O}_{3}: \mathrm{SiO}_{2}: \mathrm{PbO}=20: 20: 60\right)$ than the enamels, resulting in a yellow colour. In these lead based glasses, $\left[\mathrm{PbO}_{4}\right]^{-}$tetrahedra contribute to glass formation as the borosilicate network is highly depolymerized, most likely consisting of dimers and trimers of the network forming silicates and borates. Consequently, these glasses have a very low softening temperature $\left(\sim 300^{\circ} \mathrm{C}\right)$ and low chemical resistance to water ${ }^{31,33}$. The flux was probably added to the enamels to reduce the softening temperature and improve the adherence to the base glass.

Finally, the grisaille is a high lead glass $(40 \mathrm{~mol} \% \mathrm{PbO})$ without boron to which iron and manganese oxide pigment particles are added. High lead glasses with $<60 \%$ mol $\mathrm{SiO}_{2}$ are characterised by their high refractive index, low viscosity, and a large variation in viscosity with temperature. As for the borosilicate glasses, addition of more than $40 \%$ mol $\mathrm{PbO}$ will result in a broken silicate network. PbO cluster can form and change its role form pure modifier to an intermediate glass former ${ }^{15,39,40}$. As a result, the glass network is depolymerized, with the consequent low softening temperature."

Glasses with compositions equivalent to those of the historical enamels, grisaille and flux after subtracting the pigment particles and colourants, have been sintered; the 
corresponding molar compositions are given in Table III. These were used to explore the behaviour of glass viscosity with temperature.

$<$ Table III $>$

The thermal behaviour and glass transition temperatures corresponding to the historical enamels and synthetic glasses were determined by Differential Scanning Calorimetry, and the results are summarised in Table IV. All the historical enamels show a similar behaviour, see Figure 4. In the first heating of the powder enamel (in red in the figure) a double broad exothermic effect at the glass transition is observed, which may be related to the heterogeneous nature of the enamel, either due to some phase separation or, more likely, to an incomplete sintering process. In the second heating (in blue in Figure 4) a single exothermic effect at an intermediate temperature is then obtained, indicating that the initial double exothermic process resulted from incomplete sintering rather than the presence of a phase separation. This idea is reinforced by the fact that this phenomenon does not happen for the synthetic glasses, which in the first heating already show a single exothermic effect. The second heating DSC curves corresponding to all the historical enamels are shown in Figure 5.

$<$ Figure 4 $>$

$<$ Table IV $>$

All the colour enamels show similar $\mathrm{T}_{\mathrm{g}}$ with values of about $440^{\circ} \mathrm{C}$, with the exception of E122 with $\mathrm{T}_{\mathrm{g}}$ of about $408^{\circ} \mathrm{C}$ which is particularly high in lead and boron poor, and E89 which despite having a similar basic composition to other blue enamels contains all the copper $(5.3 \% \mathrm{CuO})$ dissolved $\left(\right.$ as $\mathrm{Cu}^{+}$and $\left.\mathrm{Cu}^{2+}\right)$, which acts as glass modifier ${ }^{41}$.

$<$ Figure 5 $>$ 
The glass transition temperature of the grisaille is significantly lower $\left(\sim 420^{\circ} \mathrm{C}\right)$ and of the flux even lower $\left(\sim 300^{\circ} \mathrm{C}\right)$. The values obtained are in good agreement with those measured from the synthetic glasses.

The behaviour of glass viscosity with temperature was determined for the synthetic glasses. The different fixed viscosity points defined for HSM are summarised in Table $\mathbf{V}^{26,27}$. The first shrinkage $(\log (\eta(\mathrm{Pa} \cdot \mathrm{s})=8.1-9.1)$ corresponds to a value of the viscosity ten times smaller than those of the deformation point, while the softening point determined $(\log (\eta(\mathrm{Pa} \cdot \mathrm{s})=5.1-5.3)$ corresponds to a viscosity ten times smaller than those of the Littleton softening point.

$<$ Table V $>$

The softening point of our synthetic glasses is one of the critical temperatures, varying between $583^{\circ} \mathrm{C}$ and $617^{\circ} \mathrm{C}$, the highest for the lead richer glasses, and even higher $\left(686^{\circ} \mathrm{C}\right)$ for the glass used for the grisaille. In general, the softening temperature increases with increasing $\mathrm{SiO}_{2}$ content of the lead-zinc borosilicate glasses. On the other hand, the optimal temperature range for the base glass is between the glass transition temperature and the softening point; it has to be as high as possible to improve the interatomic diffusion and consequently the adherence of the enamel to the glass. The glass transition temperature and the Littleton softening temperatures for the window glass from a Modernist house in Barcelona (casa Amatller) are $575^{\circ} \mathrm{C}$ and $744^{\circ} \mathrm{C}{ }^{42}$ respectively. The glass transition temperature is high and very close to the softening temperature of the enamels (between $583^{\circ} \mathrm{C}$ and $617^{\circ} \mathrm{C}$ ). On the contrary, the modern blown glass (from 1950) has a very low glass transition temperature of $537^{\circ} \mathrm{C}$ and a similar Littleton softening temperature of $733^{\circ} \mathrm{C}$. Consequently, the adherence of the enamels to the Modernist window glass would have a narrow firing temperature range. The master glazier might have been tempted to add more flux to decrease the softening temperature of the enamels and improve the adherence without raising the firing temperature. However, in such cases the enamels became more lead-rich and hence less stable, in particular with a lower chemical resistance to water corrosion ${ }^{31}$. This may explain the deterioration of the enamels. 
High lead glasses such as those used in the grisailles (40 mol\% $\mathrm{PbO}$ ) have a higher softening temperature $\left(686^{\circ} \mathrm{C}\right)$ than lead borosilicate glasses, and therefore need a higher firing temperature. Higher lead glasses which have a lower firing temperature have a yellowish colour and are less stable; consequently, the use of lead-zinc borosilicate glass for the production of enamels was a great discovery. However, their adherence also depends on the composition of the base glass. As we have noted the introduction of the Leblanc process for the production of sodium carbonate from sodium chloride is known to have changed the composition of blown window glasses decreasing the amount of stabilisers required. Moreover, at the beginning of the $20^{\text {th }}$ century, the Fourcault process (1910-1918), which replaced blowing with gravity to produce a thin sheet of window glass, was introduced ${ }^{20}$ forcing the modification of the window glass composition. What is true is whatever the reason, base glasses of different composition were used in the Catalan Modernist period, and the master glazier had to adapt their enamel compositions to them, and still may have problems with specific enamels/base glass pairs. In fact, the addition of lead borate as flux in the enamels was already censured by Barff in the $19^{\text {th }}$ century ${ }^{14}$, who indicated that although it was very good flux, it was also easily altered by air moisture. In fact, only those enamels with the right composition $\left(\mathrm{B}_{2} \mathrm{O}_{3}: \mathrm{SiO}_{2}\right.$ between $2: 3$ and $2: 1$ adding between 30 and $\left.40 \% \mathrm{PbO}\right)$ will be stable and show a reasonable high water resistance. The blue and green enamels from Lacroix, Wengers and l'Hospied studied herewith have the right composition. However, the addition of flux by the master glazier to favour the adherence of the enamels to the base glass, made them less stable.

Finally, the presence of pigment particles is another parameter which has to be taken into account; pigment particles may react with the enamel during the firing. For instance lead antimonate $\left(\mathrm{Pb}_{2}(\mathrm{Sb}, \mathrm{Sn})_{2} \mathrm{O}_{7}\right)$ and tin oxide $\left(\mathrm{SnO}_{2}\right)$ are known to crystallise during the firing. In particular, in the grisailles, melanotekite, a lead rich iron silicate $\left(\mathrm{Pb}_{2}(\mathrm{Fe}, \mathrm{Mn})_{2} \mathrm{Si}_{2} \mathrm{O}_{9}\right)$ and jacobsite $\left(\mathrm{Fe}_{2} \mathrm{MnO}_{4}\right)$ are obtained during the firing. The grisaille softening point is too high, and consequently it is probable that some flux was added to it. Lower firing temperatures and the more lead-rich glass obtained by adding some flux, produce the crystallisation of other lead richer compounds such as barysilite, $(\mathrm{Fe}, \mathrm{Mn}) \mathrm{Pb}_{8}\left(\mathrm{Si}_{2} \mathrm{O}_{7}\right)_{3}$ which has been identified in other contemporary grisailles ${ }^{2}$. Finally, adding some boron in to a lead rich glass is expected to produce a phase separation which may affect the stability of the grisaille. 


\section{Conclusions}

The chemical composition, pigments and softening temperatures of the Modernist blue and green enamels, flux and grisaille used in one of the most important stained glass workshops from the Modernist period in the city of Barcelona have been determined. A lead-zinc borosilicate glass $\left(30-40 \% \mathrm{PbO}, 0-15 \% \mathrm{ZnO}, 15-19 \% \mathrm{~B}_{2} \mathrm{O}_{3}\right)$ with softening temperatures between $583^{\circ} \mathrm{C}$ and $617^{\circ} \mathrm{C}$ was mixed with pigment particles and a flux $\left(82 \% \mathrm{PbO}, 9 \% \mathrm{~B}_{2} \mathrm{O}_{3}\right)$ with a lower softening temperature $\left(477^{\circ} \mathrm{C}\right)$ was added if necessary. The lead zinc borosilicate glass is characterised by the low softening temperatures, a thermal expansion coefficient matching those of the soda-lime base glass and high resistance to chemical corrosion, in particular to water corrosion. The glass transition temperature determined from a contemporary base glass is very close $\left(575^{\circ} \mathrm{C}\right)$ to the softening temperatures of the enamels which would have limited their adherence. As a consequence, the addition of some flux may have been common in the period. In such cases, the enamels became more lead rich and their chemical stability was lowered. This might have been particularly important in the period studied as the introduction of new chemical manufacturing processes is known to have led to changes in the composition of the blown base glasses used. The grisaille is made of a high lead glass $(70 \% \mathrm{PbO})$ and it has a higher softening temperature $\left(\sim 686^{\circ} \mathrm{C}\right)$, which would have required the addition of flux which would make it less stable to chemical corrosion. Moreover, the reactivity of the pigment particles with the glass during the enamels firing may also affect the firing temperature and mechanical stability.

\section{Acknowledgements}

We are grateful to the funds received from Ministerio de Ciencia e Innovación (Spain) project MAT2016-N0748719-R and Generalitat de Catalunya project 2017 SGR 00042. We are particularly grateful to Jordi Bonet from J.M. Bonet Vitralls S.L. who kindly supplied all the materials from the Rigalt, Granell \& cia workshop as well as historic glasses. Special thanks are given to Dr. Maite Garcia Vallès and Mariona Tarragó for their help with the HSM measurements. 


\section{References}

1. Nieto Alcaide V. La vidriera del Renacimiento en España, artes y artistas (Stain glass of the Renaissance in Spain, arts and artists). Madrid: Instituto Velazquez del Consejo Superior de Investigaciones Científicas, 1970; p. 9-14.

2. Pradell T, Murcia S, Ibáñez R, Molina G, Liu C, Molera J, et al. Materials, techniques and conservation of historic stained glass "grissailles". Int. J. App. Glass Sci. 2016; 7: $41-58$

3. Thomas A. Le Vitrail a l'Exposition Universelle (Stain glass in the Universal Exhibition), In: L’Art Décorative, París, 1900; p. 179 -187.

4. Gil Farré N. El taller de vitralls modernista Rigalt, Granell \& Cia. (1890-1931) (The Modenist stain glass workshop of Rigalt, Granell \& Co. (1890-1931)). phD thesis. Universitat de Barcelona, 2013.

5. Verità M. Modern and ancient glass: nature, composition and deterioration mechanisms. In: Scienze e Materiali del Patrimonio Culturale, 8, The Materials of Cultural Heritage in their environment. 2006; p. 119-132.

6. Verità M. Composition, structure et mechanism de deterioration des grisailles (Compositin, structure and mechanism of deterioration of grisailles). In: Grisailles, jaune d'argent, sanguine, émail et peinture à froid. Dossier de la Comission Royale des monuments, sites et fouilles 3, Forum pour la Conservation et la Restauration des Vitraux, 1996; p. 61-68.

7. Schalm O, Van der Linden V, Frederickx P, Luyten S, Van der Snickt G, Caen J, Schryvers D, et al. Enamels in stained glass Windows: Preparation, chemical composition, microstructure and causes of deterioration. Spectrochim. Acta B 2009; 64 812-820.

8. Van der Snikt G, Schalm O, Caen J, Janessens K, Schreiner M. Blue enamel on sixteenth and seventeenth-century window glass: deterioration, microstructure, composition and preparation, Stud. Conserv. 2006; 51(3): 212-222.

9. Attard-Montalto N, Shortland A. $17^{\text {th }}$ century blue enamel on window glass from the cathedral of Christ Church, Oxford: Investigating its deterioration mechanism. J. Cult. Herit. 2015; 16: 365-371. 
10. Machado A, Vilarigues M. Cobalt blue - reproduction and characterisation of blue enamel recipes from The Handmaid to the Arts by Robert Dossie. European J. Glass Sci. Tech. A. 2016: 57(4); 131-140

11. Brain C, Brain S. The development of lead-crystal glass in London and Dublin 1672-1682: a reappraisal. Glass Technol.: Eur. J. Glass Sci. Technol. A. 2016; 57(1): $37-52$.

12. Day LF. Windows a book about stained and painted glass. Batsford BT editor. New York: Charles Scribner's Sons, 1909.

13. Gilchrist A. The tears wept by our windows: sever paint loss from stained glass windows of the Mid-Nineteenth Century. Vidimus. 2012; 64 Features

14. Barff FS. Silicates, silicides, glass and glass painting. J. Soc. of Arts.1872; 20(1034) 841-852.

15. Vogel W. Glass chemistry. Berlin: Springer Verlag; 1992.

16. Beltran M, Bonet J., Pradell T. Enamel Deterioration: The thermal properties of Modernist enamels and stained glass from the city of Barcelona. Art at the Surface: Creation, Recognition and Conservation. 2017; 102-112.

17. Greer AL. Through a Glass, lightly. Nature. 1999; 402(6758): 132-133.

18. Kauzmann W. The nature of the glassy state and the behaviour of liquids at low temperatures. Chem. Rev. (1948); 43(2): 219-256.

19. Dungworth D. The value of Historic window glass. The Historic Environment. 2011; 2(1): 21-48.

20. Max Mühlig J. Notes on the early development of the Foucault process. The development in Belgium. J. Soc. Glass Tech. 1933; 17: T145-T148.

21. Lacroix A. Des couleurs vitrifiables et de leur employ pour la peinture sur porcelain, faience, vitraux. (About the glassy colours and their use for the painting on porcelain, faience, stain glass). Paris: Chez A. Lacroix; 1872.

22. Grace's guide to British Industrial History. https://www.gracesguide.co.uk/

23. Gratuze B, Blet-Lemarquand J, Barrandon JN. Mass Spectrometry with laser sampling: A new tool to characterize Archaeological materials. J. Radioanal. Nucl. Chem. 2001; 247: 645-656. 
24. Shortland AJ, Rogers N, Eremin K. Trace Element Discriminants between Egyptian and Mesopotamian Late Bronze Age glasses. J. Archaeol. Sci. 2007; 34: 781-789.

25. Guo X, Potuzak M, Mauro JC, Allan DC, Kiczenski TJ, Yue Y. Unified approach for determining the enthalpic fictive temperature of glasses with arbitrary thermal history. J. Non-Cryst. Solids. 2011; 357: 3230-3236.

26. Mazurin OV. Problems of compatibility of the values of glass transition temperatures published in the world literature. Glass Phys. Chem. 2007; 33(1): 22-36.

27. Scholze H. Der Einfluss von Viskositat und Oberflachenspannung auf erhitzungsmikroskopische Messungen an Glasern (Influence of viscosity and surface tension on Hot Stage Microscopy measurements on glasses). Ber. Dtsch. Keram. Ges. 39; 1962: 63-68.

28. Garcia-Valles M, Hafez HI, Cruz-Matías, Vergés E, Aly MH, Nogués J, Ayala D, Martinez S. Calculation of viscosity-temperature curves for glass obtained from four wastewater treatment plants in Egypt. J. Therm. Anal. Calorim. 2013; 111(1): 107-114.

29. Pascual MJ, Duran A, Prado MO. A new method for determining fixed viscosity points of glasses. Europ. J. Glass Sci. Tech. B: Phys. Chem. of Glasses. 2005; 46:(5) $512-520$.

30. Montanari F, Miselli P, Leonelli C, Boschetti C, Henderson J, Baraldi P. Calibration and use of the Heating Microscope for indirect evaluation of the viscosity and meltability of Archaeological glasses. Int. J. App. Glass Sci. 2014; 5(2):161-177.

31. Petrovskaya TS. Properties of lead borosilicate glasses: The effect of the structure. Glass Ceram. 1997; 54(11-12): 347-350.

32. Möncke D, Tricot G, Winterstein-Beckmann A, Wondraczek L, Kamitsos EI. On the connectivity of borate tetrahedra in borate and borosilicate glasses. Phys. Chem. Glasses. 2015; 56(5): 203-211.

33. Brungs MP, Cartney ER. Structure of sodium borosilicate glasses. Phys. Chem. Glasses. 1975; 16: 48-52.

34. Bunker BC, Tallant DR, Kirkpatrick RJ, Turner GL. Multinuclear nuclear magnetic resonance and Raman investigation of sodium borosilicate glass structures. Phys. Chem. Glasses. 1990; 31: 30-41. 
35. Winterstein-Beckmann A, Möncke D, Palles D, Kamitsos EI, Wondraczek L. Raman spectroscopic study of structural changes induced by micro-indentation in low alkali borosilicate glasses. J. Non-Cryst. Solids. 2014; 401: 110-114.

36. Möncke D, Tricot G, Ehrt D, Kamitsos EI. Connectivity of borate and silicate groups in a low-alkali borosilicate glass by vibrational and 2D NMR spectroscopy. J. Chem. Technol. Metallurgy. 2015; 50(4): 381-386.

37. Möncke D, Kamitsos EI, Palles D, Limbach R, Winterstein-Beckmann A, Honma T, et al. Transition and post-transition metal ions in borate glasses: Borate ligand speciation, cluster formation, and their effect on glass transition and mechanical properties. J. Chem. Phys. 2016; 145(12): 124501.

38. Wu JM, Huang HL. Microwave properties of zinc, barium and lead borosilicate glasses, J. Non-Cryst. Solids. 1999; 260: 116-124.

39. Wang PW, Zhang L, Structural role of lead in lead silicate glasses derived from XPS spectra. J. Non-Cryst. Solids. 1996; 194: 129-134.

40. Kohara S, Ohno H, Takata M, Usuki T, Morita H, Suzuya K, et al. Lead silicate glasses: Binary network-former glasses with large amounts of free volume. Phys. Rev. B. 2010; 82: 134209 .

41. Yao ZY, Möncke D, Kamitsos EI, Houizot P, Célarié F, Rouxel T, et al. Structure and mechanical properties of copper-lead and copper-zinc borate glasses. J. Non-Cryst. Solids. 2016; 435: 55-68.

42. Flügel A. Glass viscosity calculation based on a global statistical modelling approach. Europ. J. Glass Sci. Tech. A. 2007; 48(1): 13-30. 


\section{Figure cations}

Figure 1. Image of a Modernist Stained glass showing the characteristic blue enamel detaching from the glass base.

Figure 2. Images of the blue and green enamels produced from the Rigalt, Granell \& cia workshop powders.

Figure 3. XRD patterns corresponding to the crystalline phases of the pigments found in the enamels and grisaille.

Figure 4. DSC curves obtained for the enamels related to the glass transition temperature. The first run shows a double broad exothermic effect which indicates the heterogeneity of the enamel powder, the second run shows a homogeneous glass.

Figure 5. DSC curves obtained after a second run for the (A) blue enamels and (B) green enamels. 
Table I. LA-ICP-MS analysis of the blue and green enamels, the flux used and also the grisaille prepared from the Granell workshop materials and a glass from the period (1900) and a modern glass (1950). The standard deviation over three measurements is given in brackets. The enamels marked with * have crystalline pigment particles : E33, cobalt aluminate $\left(\mathrm{CoAl}_{2} \mathrm{O}_{4}\right)$; E114 and E115 cassiterite $\left(\mathrm{SnO}_{2}\right) ; \mathrm{E} 34, \mathrm{Naples}$ yellow $\left(\mathrm{Pb} 2(\mathrm{Sb}, \mathrm{Sn})_{2} \mathrm{O}_{7}\right)$ and cochromite $\left(\mathrm{Co}(\mathrm{Cr}, \mathrm{Al})_{2} \mathrm{O}_{4}\right)$ and $\mathrm{G1}$, hematite $\left(\mathrm{Fe}_{2} \mathrm{O}_{3}\right)$, melanotekite $\left(\mathrm{Pb}_{2}(\mathrm{Fe}, \mathrm{Mn})_{2} \mathrm{Si}_{2} \mathrm{O}_{9}\right)$ and jacobsite $\left(\mathrm{Fe}_{2} \mathrm{MnO}_{4}\right)$

\begin{tabular}{|c|c|c|c|c|c|c|c|c|c|c|c|c|c|c|c|c|c|c|}
\hline Company & color & $\% \mathrm{wt}$ & $\mathrm{B}_{2} \mathrm{O}_{3}$ & $\mathrm{Na}_{2} \mathrm{O}$ & $\mathrm{MgO}$ & $\mathrm{Al}_{2} \mathrm{O}_{3}$ & $\mathrm{SiO}_{2}$ & $\mathrm{~K}_{2} \mathrm{O}$ & $\mathrm{CaO}$ & $\mathrm{Cr}_{2} \mathrm{O}_{3}$ & $\mathrm{MnO}$ & $\mathrm{Fe}_{2} \mathrm{O}_{3}$ & $\mathrm{CoO}$ & $\mathrm{CuO}$ & $\mathrm{ZnO}$ & $\mathrm{SnO}_{2}$ & $\mathrm{Sb}_{2} \mathrm{O}_{5}$ & $\mathrm{PbO}$ \\
\hline W & blu & $523 *$ & 11.1 & 2.76 & 0.53 & 13.9 & 11.4 & 0.118 & 0.70 & & & 0.35 & 7.7 & & 9.2 & 0.16 & & 41.9 \\
\hline wengers & olue & E30" & $(0.3)$ & $(0.1)$ & $(0.01)$ & $(0.6)$ & $(0.1)$ & $(0.002)$ & $(0.03)$ & & & $(0.01)$ & $(0.1)$ & & $(0.1)$ & $(0.01)$ & & $(0.3)$ \\
\hline \multirow{10}{*}{ Lacroix } & \multirow{4}{*}{ blue } & \multirow{2}{*}{ E114* } & 15.4 & 0.64 & & 1.4 & 8.7 & 0.27 & 0.43 & & & & 0.29 & & 15.1 & 0.5 & & 57.2 \\
\hline & & & $(0.2)$ & $(0.05)$ & & $(0.1)$ & $(1.2)$ & $(0.02)$ & $(0.02)$ & & & & $(0.04)$ & & $(0.9)$ & $(0.1)$ & & $(0.4)$ \\
\hline & & \multirow{2}{*}{ E115* } & 18.2 & 0.65 & & 0.46 & 7.7 & 0.267 & 0.43 & & & & 0.84 & & 14.6 & 0.17 & & 56.5 \\
\hline & & & $(0.3)$ & $(0.01)$ & & $(0.02)$ & $(0.1)$ & $(0.002)$ & $(0.01)$ & & & & $(0.09)$ & & $(0.4)$ & $(0.03)$ & & $(0.3)$ \\
\hline & \multirow{6}{*}{ green } & \multirow[t]{2}{*}{ E121 } & 15.2 & 0.87 & & 0.52 & 6.90 & 0.17 & 0.50 & 0.4 & & & 2.0 & & 13.9 & & 0.071 & 59.2 \\
\hline & & & $(0.4)$ & $(0.05)$ & & $(0.01)$ & $(0.02)$ & $(0.01)$ & $(0.01)$ & $(0.03)$ & & & $(0.03)$ & & $(0.2)$ & & $(0.001)$ & $(0.3)$ \\
\hline & & \multirow{2}{*}{ E34* } & 8.1 & 2.04 & 0.40 & 5.9 & 10.7 & 0.50 & 0.33 & 10.8 & & 0.202 & 6.5 & 0.3 & 1.85 & 0.91 & 1.23 & 50 \\
\hline & & & $(0.3)$ & $(0.07)$ & $(0.06)$ & $(0.3)$ & $(0.3)$ & $(0.05)$ & $(0.03)$ & $(0.6)$ & & $(0.003)$ & $(0.4)$ & $(0.1)$ & $(0.01)$ & $(0.02)$ & $(0.04)$ & (1) \\
\hline & & \multirow[t]{2}{*}{ E89 } & 16.4 & 1.73 & & 0.45 & 8.5 & 0.21 & 0.66 & 0.2 & & 0.162 & & 5.3 & 12.4 & & & 53.9 \\
\hline & & & $(0.04)$ & $(0.07)$ & & $(0.01)$ & $(0.1)$ & $(0.01)$ & $(0.01)$ & $(0.01)$ & & $(0.008)$ & & $(0.3)$ & $(0.2)$ & & & $(0.2)$ \\
\hline \multirow{2}{*}{ L'Hospied } & \multirow{2}{*}{ blue } & \multirow{2}{*}{ E122 } & 3.8 & 0.15 & & 0.8 & 23.2 & 0.04 & 0.24 & & & & 0.12 & & 0.22 & & & 71.2 \\
\hline & & & $(0.2)$ & $(0.05)$ & & $(0.1)$ & $(1.2)$ & $(0.01)$ & $(0.05)$ & & & & $(0.02)$ & & $(0.03)$ & & & (1.5) \\
\hline \multirow{2}{*}{ Lacroix } & \multirow{2}{*}{ flux } & \multirow{2}{*}{$\mathrm{F} 1$} & 9.1 & & & 0.90 & 9.15 & & 0.2 & & & 0.10 & & & & & & 80.1 \\
\hline & & & $(0.1)$ & & & $(0.06)$ & $(0.09)$ & & $(0.06)$ & & & $(0.01)$ & & & & & & $(0.2)$ \\
\hline \multirow{2}{*}{ Granell } & \multirow{2}{*}{ grisaille } & \multirow{2}{*}{$\mathrm{G} 1 *$} & & 0.20 & & 0.5 & 19.9 & 0.14 & 0.1 & & 6.5 & 21.9 & & & & & & 50.4 \\
\hline & & & & $(0.08)$ & & $(0.0)$ & $(0.4)$ & $(0.02)$ & $(0.02)$ & & $(0.1)$ & $(0.2)$ & & & & & & $(0.4)$ \\
\hline \multirow{2}{*}{$\begin{array}{c}1900 \\
\text { Amatller house }\end{array}$} & \multirow{2}{*}{ blown glass } & \multirow{2}{*}{ GL1 } & 0.01 & 12.1 & 0.41 & 0.61 & 72.5 & 0.22 & 13.8 & & & 0.277 & & & & & & \\
\hline & & & $(0.00)$ & $(0.1)$ & $(0.01)$ & $(0.01)$ & $(0.3)$ & $(0.01)$ & $(0.4)$ & & & $(0.002)$ & & & & & & \\
\hline \multirow{2}{*}{1950} & \multirow{2}{*}{ blown glass } & \multirow{2}{*}{ GL2 } & 0.03 & 13.4 & 4.22 & 0.71 & 74.5 & 0.14 & 6.50 & & & 0.120 & & & & & & 0.2 \\
\hline & & & $(0.01)$ & $(0.3)$ & $(0.08)$ & $(0.03)$ & $(0.4)$ & $(0.01)$ & $(0.02)$ & & & $(0.003)$ & & & & & & $(0.1)$ \\
\hline
\end{tabular}


Table II. Cie Lab* color coordinates obtained from the Transmittance UV-Vis spectra measured. $\mathrm{L}^{*}$ lightness, $\mathrm{a}^{*}$ and $\mathrm{b}^{*}$ color coordinates, chroma, $c^{*}=\sqrt{a^{*^{2}+b^{* 2}}}$, hue, $h^{*}$ $=\tan ^{-1}\left(b^{*} / a^{*}\right)$ and saturation, $s^{*}=c^{*} / \sqrt{c^{* 2}+L^{* 2}}$.

\begin{tabular}{ccccccccc}
\hline Company & color & enamel & $L^{*}$ & $a^{*}$ & $b^{*}$ & $c^{*}$ & $h^{*}()$ & $s(\%)$ \\
\hline Wengers & blue & E33 & 40.7 & -7.8 & -35.3 & 36.2 & 257.6 & 66.4 \\
\hline \multirow{4}{*}{ Lacroix } & \multirow{4}{*}{ blue } & E114 & 39.4 & -1.6 & 1.2 & 2.1 & 242.6 & 5.2 \\
\cline { 2 - 9 } & & E115 & 35.5 & 3.3 & -4.3 & 5.4 & 307.2 & 15.0 \\
\cline { 3 - 9 } & \multirow{2}{*}{ green } & E121 & 77.2 & -9.2 & 13.3 & 16.1 & 124.6 & 20.5 \\
\cline { 2 - 8 } & & E34 & 11.1 & -3.9 & 8.1 & 9.0 & 115.4 & 63.0 \\
\cline { 2 - 8 } & E89 & 86.1 & -2.5 & 4.0 & 4.7 & 122.6 & 5.5 \\
\hline L'Hospied & blue & E122 & 31.3 & -0.4 & 1.8 & 1.9 & 202.5 & 6.0 \\
\hline
\end{tabular}


Table III. Chemical compositions of the synthetic enamels determined after the chemical composition of the historical enamels after subtracting the pigment particles and colourants.

\begin{tabular}{ccccccc}
\hline sample & $(\%$ mol $)$ & & $\mathrm{SiO}_{2}$ & $\mathrm{PbO}$ & $\mathrm{B}_{2} \mathrm{O}_{3}$ & $\mathrm{ZnO}$ \\
\hline $\mathrm{M} 1$ & Grisaille (Granell) & transparent & 60 & 40 & 0 & 0 \\
\hline M2 & Flux (Lacroix) & $\begin{array}{c}\text { transparent } \\
\text { yellow }\end{array}$ & 20 & 60 & 20 & 0 \\
\hline M3 & $\begin{array}{c}\text { blue/green } \\
\text { (Lacroix/Wengers) }\end{array}$ & transparent & 20 & 30 & 30 & 20 \\
\hline M4 & $\begin{array}{c}\text { opaque } \\
\text { (Lacroix) }\end{array}$ & $\begin{array}{c}\text { white } \\
\text { opalescent }\end{array}$ & 50 & 30 & 15 & 5 \\
\hline M5 & blue (l'Hospied) & transparent & 50 & 40 & 10 & 0 \\
\hline M6 & green (Lacroix) & transparent & 35 & 40 & 20 & 5 \\
\hline & & & & & & \\
\hline
\end{tabular}


Table IV. Glass transition temperatures measured by DSC corrresponding to the historical enamels, grisaille, flux and also to the synthetic glasses produced with compositions equivalent to the historical enamels. ${ }^{1}$ For the base glasses, the glass transition temperature, deformation and Littleton softening temperatures with $\log (\eta(\mathrm{Pa} \cdot \mathrm{s}))=12.5,10.5$ and 6.6 respectively are calculated after $\mathrm{Flügel}^{38}$.

\begin{tabular}{|c|c|c|c|c|c|}
\hline & Company/After & color & & $\mathrm{T}_{\mathrm{g}}$ & $\mathrm{T}_{\mathrm{d}}-\mathrm{T}_{\mathrm{s}}$ \\
\hline \multirow{9}{*}{$\begin{array}{c}\text { Historical } \\
\text { enamels }\end{array}$} & Wengers & blue & E33 & 435 & \\
\hline & \multirow{5}{*}{ Lacroix } & \multirow{2}{*}{ blue } & E114 & 441 & \\
\hline & & & E115 & 440 & \\
\hline & & \multirow{3}{*}{ green } & E121 & 428 & \\
\hline & & & E34 & 438 & \\
\hline & & & E89 & 407 & \\
\hline & L'Hospied & blue & E122 & 408 & \\
\hline & Lacroix & flux & F1 & 360 & \\
\hline & Granell & grisaille & G1 & 435 & \\
\hline \multirow{2}{*}{$\begin{array}{c}\text { Historical } \\
\text { Base glasses }\end{array}$} & $\begin{array}{c}1900 \\
\text { Amatller } \\
\text { house }\end{array}$ & $\begin{array}{l}\text { blown } \\
\text { glass }\end{array}$ & GL1 & $575^{1}$ & $613-744^{1}$ \\
\hline & 1950 & $\begin{array}{l}\text { blown } \\
\text { glass }\end{array}$ & GL2 & $537^{1}$ & $581-733^{1}$ \\
\hline \multirow{6}{*}{$\begin{array}{l}\text { Synthetic } \\
\text { glasses }\end{array}$} & Granell & grisaille & M1 & 420 & \\
\hline & Lacroix & flux & M2 & 299 & \\
\hline & Lacroix/Wengers & blue/green & M3 & 448 & \\
\hline & Lacroix & opaque blue & M4 & 442 & \\
\hline & l'Hospied & blue & M5 & 437 & \\
\hline & Lacroix & opaque green & M6 & 432 & \\
\hline
\end{tabular}


Table V. Temperatures of the synthetic glasses at fixed values of the viscosity after ${ }^{1}$ Pascual and ${ }^{2}$ Scholze.

\begin{tabular}{cccccccc}
\hline Sample & $\log (\eta(\mathrm{Pa} \cdot \mathrm{s}))$ & M1 & M2 & M3 & M4 & M5 & M6 \\
\hline Flow point & $2.4^{1}-3.1^{2}$ & 816 & 589 & 713 & 923 & 792 & 723 \\
\hline Half ball point & $3.1-3.6$ & 789 & 515 & 640 & 810 & 701 & 669 \\
\hline Ball point & $4.4-$ & 763 & 514 & 640 & 704 & 677 & 642 \\
\hline Softening point & $5.3-5.1$ & 686 & 477 & 590 & 617 & 613 & 583 \\
\hline Maximum shrinkage point & $6.8-7.2$ & 650 & 476 & 586 & 597 & 608 & 571 \\
\hline First shrinkage point & $8.1-9.1$ & 600 & 457 & 522 & 512 & 533 & 530 \\
\hline
\end{tabular}




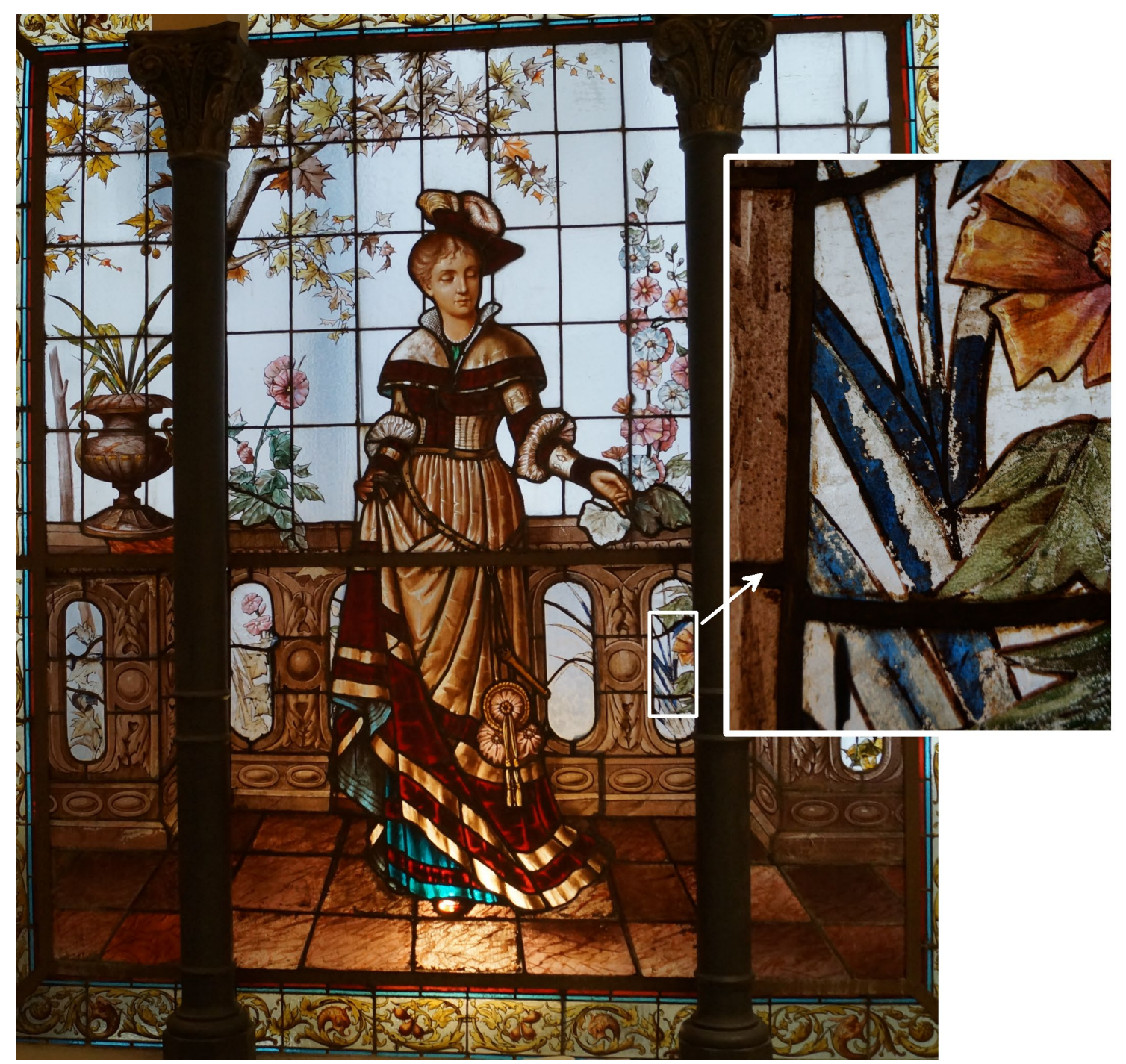




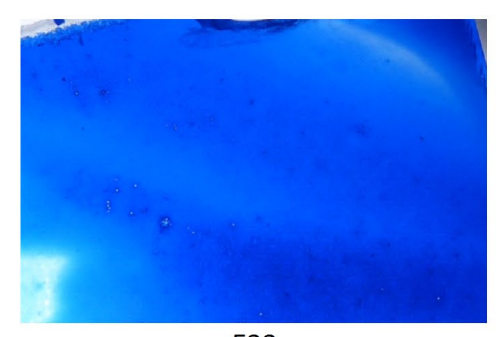

E33

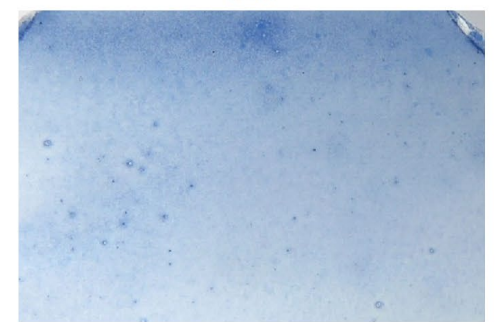

E114

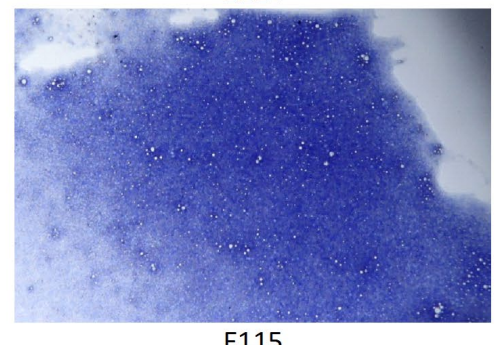

E115

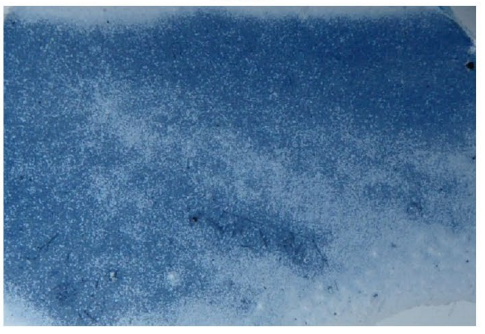

E122

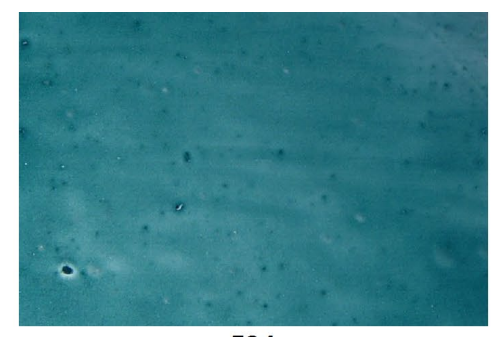

E34

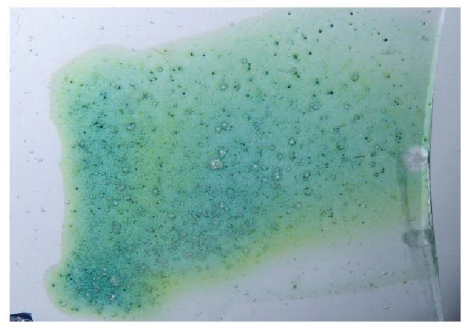

E89

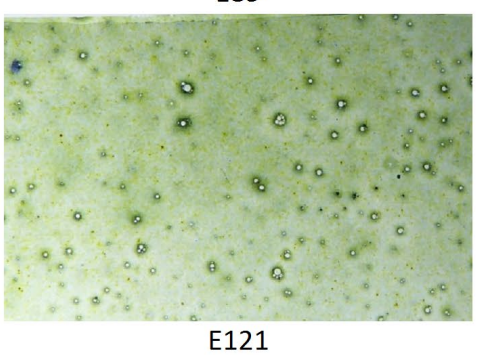

E121 


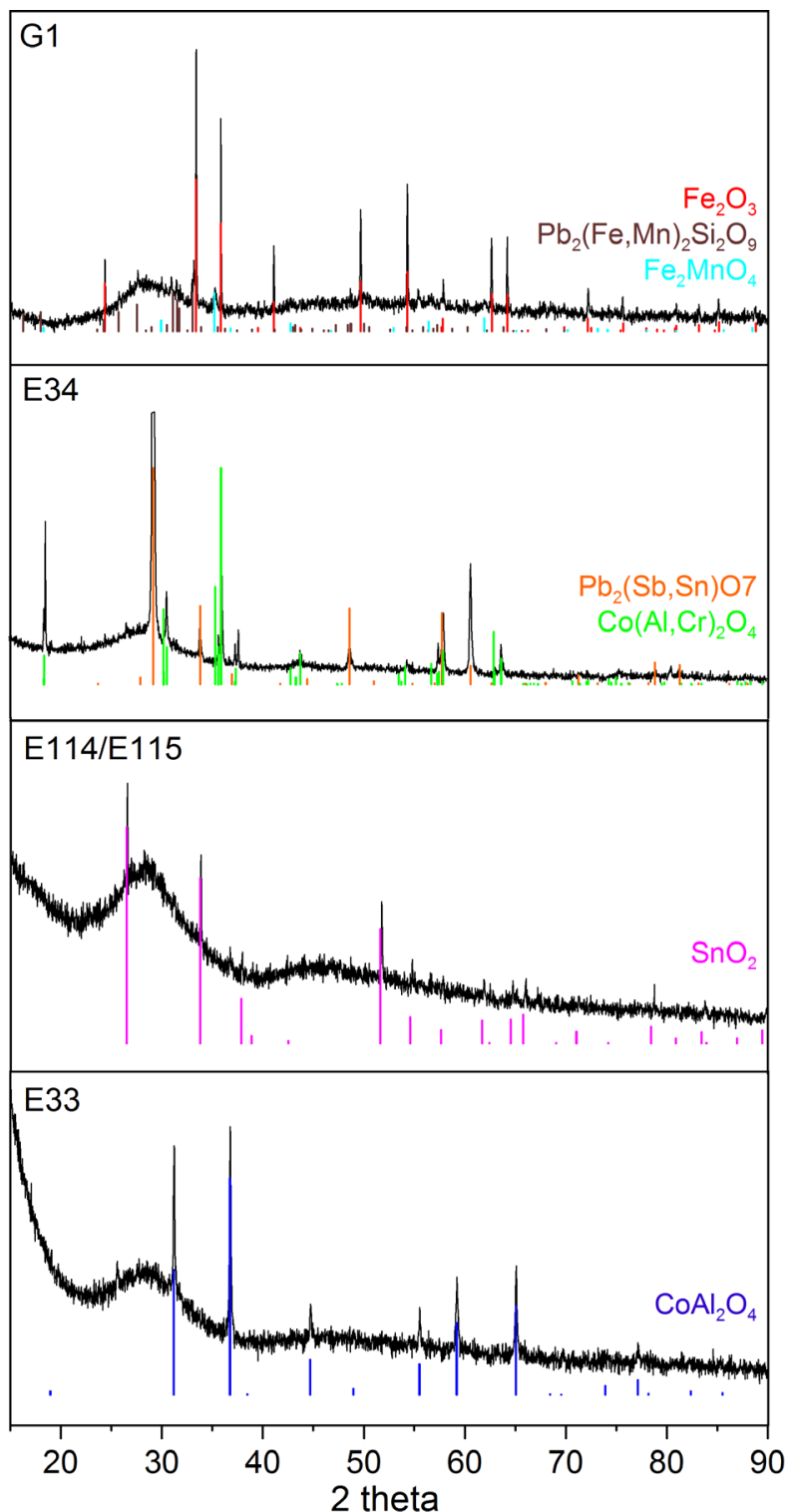




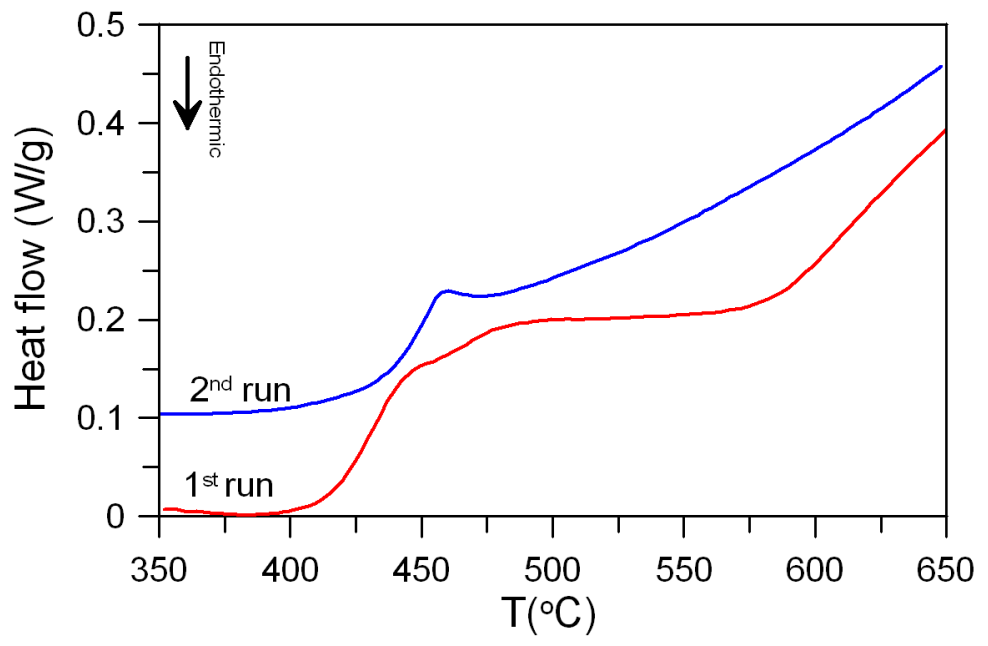



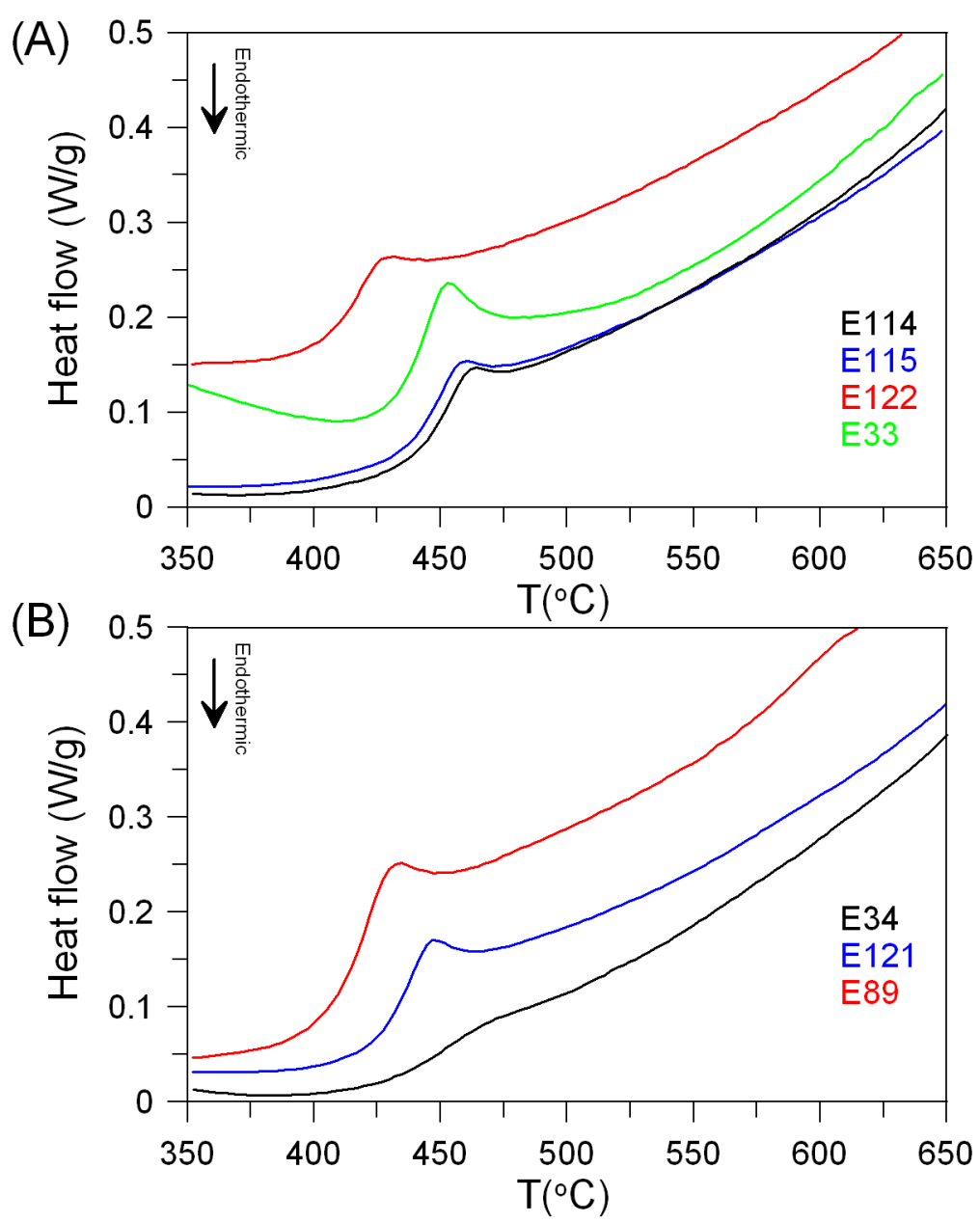